\title{
I Am Torn Between The Two... A Hybrid Process Perspective Of Buyer-Supplier Relationships
}

Hervé Fenneteau, PhD, Université Montpellier I, MRM, France

Gilles Paché, PhD, Aix-Marseille Université, CRET-LOG, France

\begin{abstract}
It is common, nowadays, to read in academic studies that inter-organisational exchanges are dominated by a relational way of thinking rather than a transactional one. The increasing performance of supply chains results only from longterm partnerships concluded between supply chain members, and founded on their durable engagement in order to develop and consolidate the relationship. The aim, here, is to show, on the contrary, that transactional elements are not incompatible with the relational way of thinking; they could even strengthen the partnership between supply chain members under certain conditions. The case of logistics industry is used to argue the pertinence of a hybridisation model, and not an opposition, between transactional and relational ways of thinking.
\end{abstract}

Keywords: Logistics Service Provider (LSP); Relational Marketing; Supply Chain; Hybridisation

\section{INTRODUCTION}

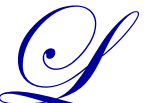

iterature in $\mathrm{B} 2 \mathrm{~B}$ marketing emphasises the evolutions in progress in the exchange between companies: the passage from a "transactional paradigm" to a "relational paradigm" (Morgan \& Hunt, 1994; Grönroos, 1996; Li \& Nicholls, 2000; Gummeson, 2008). The latter is based on the partner's will (manufacturers, large retailers, logistics service providers [LSP], etc.) to build long term and narrow relationships, durable along the supply chains. To succeed, partners develop specific investments, in transport, warehousing or information systems, to increase the performance of the exchange relationships in terms of cost, agility and service quality. The relational paradigm would mean a progressive marginalisation of the transactional paradigm founded on the regular competitive use of multiple partners, a short duration of the contract agreement, occasionally reduced to a few months, and a will to exit rapidly any exchange, including by using opportunism in Williamson's (1991) sense.

The aim of the contribution is to question the real opposition between the two models that would exclude each other mutually, in the context of the logistics industry. The inspection of the extension of the area of expertise of LSPs initially enables to understand how the relational paradigm has progressively imposed itself and what shape it assumes in the logistics industry. The observation of company practices and recent evolutions lead to question, in a second phase, the pre-eminence of this paradigm. The reality of business shows the existence of a hybridisation process that leads to consider the relational paradigm as a basis of the exchange, but compatible with the injection of transactional elements (Lacoste, 2012). In a broader sense, a hybrid process combines dimensions of two (or more) separate processes into one. In reference to the actors at the origin of the hybridisation of inter-organisational exchanges, it is thus possible to identify two types of hybridisation: the sequential and the structural hybridisation.

The theme approached refers to the mix between the relational and transactional paradigm, guiding the way to a hybridisation process. In genetics, a hybrid usually comes from the crossing of two species or two distinct varieties and the reasoning can apply to the management of organisations as soon as we cross different forms of governance. This is not really new, as the topic of "hybridisation" is closely related to similar fields, such as "coopetition" (Erikson, 2008). Indeed, hybrid institutional arrangements and organisations (alliances, networks) are broadly analysed, but 
hybridisation (or coopetition) is oftentimes discussed in relation to manufacturing industries or even manufacturing supply chains (automotive, aerospace), and rarely in the logistics industry. Indeed, most research on coopetition examined relationships between competitors in a single industry (Dagnino \& Rocco, 2011), not vertical exchanges between customers and suppliers of logistical services (or marketing services). Then again, the questions raised on the viability, performance and variable geometry of hybridisation are not examined in depth. And yet, the market and resources change, for example in urban logistics, pooling and sharing strategies cause a shift between existing relational dominant approaches towards transactional behaviour. The way to manage and to structure the organisation according to those developments constitutes a stimulant research agenda.

The paper is of exploratory and conceptual nature. It seeks to understand in which measure hybridisation leads to a more nuanced vision of the governance of relationships between the shippers and LSPs. For many years, we thought that these exchanges obeyed to two opposed registers: the transactional register, no long-lasting engagement between the parties, with exchange spots often questioned, in very short timespans; the relational register, with a longlasting engagement between the parties based on the implementation of information sharing and joint planning in the meaning of Noordewier et al. (1990) and of Rindfleisch \& Heide (1997). This dichotomous vision is reductive and it questions the way a relational arrangement will - or will not - overcome a transactional behaviour. From this point of view, we differentiate ourselves from traditional works on the coopetition where cooperation and competition are considered from the start as two natural aspects of the exchange relationship. The hybridisation alluded to in the paper refers to the surprise that may feel a supply chain member engaged in a relational arrangement when it must face a transactional episode, and what its reactions will be. We will use illustrations as weak signals of the hybrid process in an abductive perspective, understood as an approach that "allows conjecture from clues and traces" (Angué, 2009).

\section{EXTENSION OF THE AREA OF EXPERTISE OF LSPS}

One only has to read on a regular basis the professional press specialised in retail logistics to read about success stories based on an active partnership between a manufacturer (or large retailer) and its LSP, like the symbiotic relationship knotted for many years between McDonald's and Martin Brower in France. Everything seem to have been set up for supply chains to function on a relational model, with a large diversity of investments in specific assets granted by the LSPs to stabilise the inter-organisational exchanges and increase its performance. Understanding this major evolution in the logistics industry demands a preliminary clarification, at once, on the nature of the operations that LSPs manage and on the relational strategies they develop within the supply chains. A long way from the conventional stereotype that confines them in the role of modernist transporters, the LSPs have learnt to widen their offer in a significant way, as part of contracts of different nature.

\section{Historical Approach And Operational Dimensions}

With a historical perspective, manufacturers have been long-standing adepts of own account logistics. In the 1920s, they manifest the will to organise their business structure by abandoning wholesalers and independent traders, accused of hindering the implementation of an active sales policy. Examining the cases of bottled mineral water in France, Marty (2008) underlines how wholesalers were to remain present until the 1960s, before disposable packaging (without consignment) was massively adopted by manufacturers. The rationalisation of logistics would not be on the manufacturers' agenda before many decades, but the ownership of regional warehouses, although having narrow market coverage, allowed them to reach small retailers without colliding with the intermediaries' smokescreen. In other words, the well of manufacturers was to control the supply chain to accompany their marketing strategy in conquering of clients.

On their side, and nearly at the same moment, a few large French retailers like Casino understand the interest of integrating the wholesale function. The significant increase of capacities of goods storage (and consequently of purchase) shows the possibility to increase the negotiation power vis-à-vis the manufacturers by buying directly from their factories. Here again, the option chosen is the own account logistics, for lack of a relatively efficient rental storage offer. The trend reverses during the 1970s, in the United Kingdom initially. Indeed, numerous large British retailers having taken control of the wholesale function start to turn to LSPs to ensure the entire tasks linked to store purchasing. We can identify Exel Logistics as being the first modern LSP, following a partnership operation with Marks \& Spencer in the middle of the 1970s. 
Then, the outsourcing logistics movement spreads out progressively to France. The main beneficiaries are powerful road transport companies that have grown their offer and, at a lesser extent, dynamic warehouses (Fulconis $e t$ al., 2011). Indeed, these operators understood rapidly that the phenomenon of outsourcing logistics was part of a large scale movement, that is to say the specialisation of shippers in their core competences and their correlative research for external skills in terms of physical distribution. For the more dynamic road transporters, the diversification towards high added value logistics services allows to shift the bargaining with the shippers on non-price dimensions, for example the quality and reliability of services related to the actual transport of the products, thus by avoiding a part of the extremely costly hyper-competition process that are common in simple transport activities.

Today, the logistics industry appears quite heterogeneous for at least two reasons: firstly, there are companies that belong to various lines of business (road transport, converted wholesalers, logistical branches of large retailers and manufacturers, etc.); secondly, the demands of shippers are more and more specific depending on the type of product sold. Globally, a logistical service can include a large set of modular components likely to be chosen by senders and/or the addressees of the products, that is the manufacturers and/or the large retailers, and gathered depending on their unique needs. LSPs create superior value for their clients in comparison to competitors when they recognize and satisfy specific shipper needs; in this case, the LSP develop a customer-oriented relationship (Ellinger et al., 2010). According to Large et al. (2011), the LSP customer orientation then positively influence their dynamic adaptation capability and explain the LSP's competitive advantage founded on a tailored assembly of modular components for each shipper. These modular components can be divided in four categories:

- $\quad$ Transport and linked operations: pooling, organisation of delivery rounds, rental of vehicles with or without drivers, etc.

- $\quad$ Technical operations of physical distribution: handling, order preparation, reconditioning, labelling, etc.

- Management operations: warehousing and stock-keeping, management of expiry dates, processing of orders, etc.

- $\quad$ Operations of industrial or marketing characteristics: invoicing, management of after-sales services, copacking and co-manufacturing, etc.

All these operations do not have the same strategic importance, nor the same potential of market growth. Thus, the traditional transport activities (and auxiliaries) are a component that the LSPs often prefer to subcontract to small road transporters, placed in a dependency situation, to the extent that the transport is only faintly differentiating or lucrative. On the opposite side, other services with high added value are considered as major development lines, transforming certain LSPs in types of assemblers close to industrial subcontractors. It is the case of, for example, Norbert Dentressangle, Geodis, FM Logistic or Kuehne+Nagel, that have greatly grown their offer by integrating the kitting and the co-packing for the past fifteen years. The high added value services underline the main importance of customer-focused legacy as a key element for LSP to attract, retain and keep the trust of their customers (Clinton, 2008).

\section{Strategic And Contractual Dimensions}

Having for ambition to give a synthetic view of the logistics industry in Europe, partly cleared from national specificity, Cooper et al. (1993) chose to integrate the client's choice (the shipper) in their analysis; their work is still an authority twenty years later. The central ideas of the authors are to build a strategic matrix based on the client's degree of implication in the production process of the logistical service. According to Cooper et al. (1993), any logistical service can therefore be studied starting with two distinct levels. The first level, managerial and strategic, shows the task sharing between the supplier (LSP) and the user (shipper) of the service. In other words, defining who will organise the supply chain, who controls the original concept and who organises the various logistical operations, whether we speak of transport or of a broader offer associating activities on a modular platform. The second level, capacitary and contractual, indicates if the logistical services are dedicated to a single client (see Box 1), if they concern a small number of clients with the same need or, finally, if they aim at a large number of users with no specific expectation. That is, knowing under what conditions the different logistical capacities can -or cannot- be shared. Figure 1 shows that the mixing of these two levels results in the border marking of the work of LSP based on a series of contracts: customer dedicated (3 and 4), shared user (5 and 6) or common user (7 and 8). 
\begin{tabular}{l} 
Box 1. A Tailor-Made Partnership Between Norbert Dentressangle And Skitsch \\
\hline Established in Italy in 2009, Skitsch immediately made its mark on the design sector. Following the success of its Milan store, \\
the brand plans to open new points of sale in all the European capitals during 2010. Norbert Dentressangle as LSP has \\
developed a tailor-made project for Skitsch, which covers all the logistical stages, from storage to delivery to the customer. \\
"What makes this company special is both its multi-channel sales model, based on the store, paper catalogue and e-commerce, \\
and the exclusive nature of its range, says Alessandro Renzo, business development manager at Norbert Dentressangle in \\
Italia. This led us to develop two different distribution processes: one for accessories, with a fast and fluid delivery system, and \\
the other for larger furniture. Specialist teams are dedicated to the efficient running of this process and guarantee that Skitsch's \\
requirements are fulfilled. As well as assembling furniture, the employees have to provide logistics solutions. For example, if a \\
piece of furniture is too large to be installed at the customer's home, our team can dismantle and reassemble it without any \\
difficulty". In addition, Norbert Dentressangle develops appropriate packaging for each product. Moreover, the inter-linking of \\
the Norbert Dentressangle and Skitsch information systems further improves the efficiency of its e-commerce activity. At the \\
logistical platform in Castel S. Giovanni (province of Piacenza, in the north of the country), Skitsch currently has a 2,000 m ${ }^{2}$ \\
surface, which handles over 250 different products. This volume should increase in line with the growth in sales registered by \\
the brand.
\end{tabular}

Source: adapted from Talents, No. 13, Summer 2010.

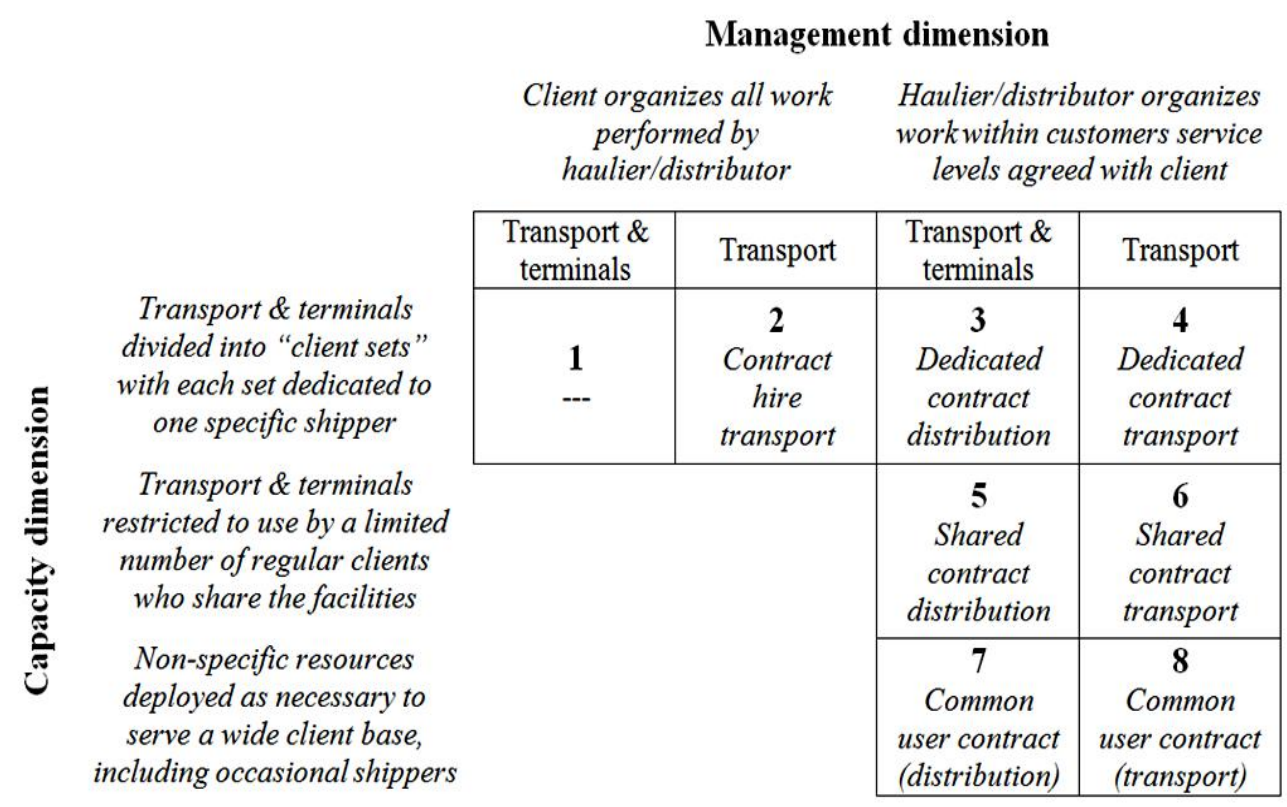

Source: adapted from Cooper et al. (1993).

Figure 1: A Typology Of Logistical Service

At the strategic level, the shippers had a determinant influence on the definition of the sharing of tasks with the LSPs. Evolution trends of the logistics industry emerge that manufacturers have voluntarily handed over a larger and larger perimeter of activities to LSPs, by committing to them in durable relationships and building shared management systems (in particular at the level of information systems). The shippers have tried to gain a competitive advantage by favouring the relational paradigm and have struggled to protect this competitive advantage through partitioning of logistics systems between competitors. Thus, while the search of economies of scale would require the LSPs to work with the larger number of possible shippers, the reference is often a dyad, or rather multiple dyads independent of one another. We are not dealing with a mass logistics consolidating by necessity of heterogeneous flows, but with tailored logistics in which the LSP try to fulfil its client's needs and to develop loyalty by suggesting customised services (Large, 2007). Being entrusted with more and more extended missions, the main LSPs progressively win in autonomy and develop a strategic thinking that leads them to explore new paths. The strategic intelligence of LSPs is largely based on their capacity to identify "nodes" in supply chains, distinct, but showing characteristics sufficiently similar to be driven in a global way, and not supply chain by supply chain. It enables them to maintain a durable competitive advantage regarding their clients. In an early way, LSPs have shown the advantage of common delivery rounds to numerous rival stores in order to reduce supplying costs. Later, they would prove, likewise, the interest of the implementation of a pooled stock management (Camman \& Livolsi, 2009). 
Even if the strategic dimension is important, it must not outshine the contractual dimension because, in the end, LSPs and shippers knit relationships of a precise type to fulfil needs regarding costs, services and reactivity. It would not be very relevant to try to establish general rules on the contracting modes between LSPs and shippers, and in particular to decide in terms of contract longevity, considering particular situations that can be encountered in supply chains. For example, depending on whether the execution of logistical operations demands (or not) specific assets that "encapsulates" a particular know-how, the nature and the duration of the contracts will not have the same shape. Thus, when a LSP implements kitting and co-packing on the behalf of a manufacturer, the duration of the relational customer dedicated contract increases significantly, generally up to numerous years (Fulconis $e t$ al., 2011), when it can last only a few weeks for a seasonal storage activity in the framework of a common user contract. Box 2 presents an example of integrated logistical solutions proposed by a large LSP in the USA, including operations of industrial or marketing characteristics.

Box 2. Providing Integrated Logistical Solutions: The Evans Distribution Systems Case

Evans Distribution Systems offers customers the opportunity to use our quality resources and flexible warehousing work force for all their contract packaging needs. By outsourcing labor intensive contract packaging needs you can save costs and increase your operational efficiencies. Our contract packaging services include: packaging, assembly, POP displays, shrink wrapping, kitting and bagging, pallet restacking, labeling, and fulfillment. Evans is one of the largest suppliers of contract packaging services to the liquor industry specializing in handling seasonal co-packing of alcoholic beverages. We are a trusted third party logistics partner that can expertly manage your packaging needs. Evans offers customers importing goods or raw materials into the U.S. for their packaging a unique opportunity to defer the payment of duty by using our foreign trade zone status. Duties are not required to be paid until the final product/package leaves the zone. Evans Distribution Systems warehousing and distribution, transportation and quality inspection services can all be supported by the contract packaging services we offer allowing customers an integrated logistical solution.

Source: Company document (2014).

The multiplication of customer dedicated contracts shows a major change in the relationship between the LSP and the shipper: the progressive interpenetration of supply chain members monitoring systems. It appears like the more appropriate answer in presence of specific assets as when it possesses such assets, the LSP is better off establishing itself in the inter-organisational exchange relationships (Medina \& Paché, 2007), given the existence of sunk costs in the case of non-renewal of contracts. It is the case for the dedicated logistical investments as the LSP will re-allocate them, with difficulty, with new clients in the short run if no demand exists outside this precise transaction. For his part, the shipper will most probably also be advantaged by a continuation of the exchange relationships as the potential abandonment of its LSP would imply a selection effort and an evaluation of a new LSP capable of offering the same dedicated assets. This results in a co-dependence situation, very favourable to the implementation of a win-win partnership. This type of relationship corresponds to the most successfully completed relational exchange. There is then a closed dyad, with a long term relationship between two partners that cooperate by proceeding with mutual adjustments and these mutually grant the other a privileged treatment: the shipper focuses its main volumes on the LSP and the latter develops a personalised offer for his partner who fulfils its demands by keeping an eye on the specifications, making specific investments, risky operations that are reserved to small number of priority clients.

\section{QUESTIONING RELATIONAL EXCHANGES}

In the exchanges between shippers and LSPs, currently, we can see the appearance of new elements of transactional nature that articulate with the relational component, without leading to its disappearance, but by resulting in hybrid relationships. The relationship only is challenged as a dominant paradigm. Three types of actors of the logistics industry are likely to introduce transactional components in the exchange obeying a purely relational perspective. It is usually the case of shippers and LSPs, but also, in a more surprising manner, of local authorities, that involve more and more systematically a certain number of logistical frameworks, in particular when it comes to urban logistics. It is also important to analyse the impacts of what we will name the sequential and structural hybridisation on the governance of inter-organisational exchanges.

\section{Actors At The Root Of Hybridisation And Types Of Hybridisation}

The purchaser of a logistical service, the shipper, is likely to step away from the relational paradigm in two ways. The first way consists in calling on the market's rules by reactivating the competition between LSPs. This can 
cause an occasional infidelity vis-à-vis the customary LSP. The latter is then deprived of a new market that would have been given to him if the shipper, its partner, had continued to reserve practically its entire flow for him. The shipper can also increase the dyad and establish a triadic sourcing, by simultaneously turning to two privileged suppliers in charge of stimulating one another (Dubois \& Freriksson, 2008). Finally, the recourse to the market can also lead to a shipper abandoning its customary LSP for good for the benefit of a more efficient LSP. We are currently witnessing the termination of certain dedicated contracts with LSPs, even when highly specific investments had been done. The Carrefour group has in this way reorganised the logistics of its textile products by breaking up with certain LSPs. The disappearance of economic growth and the necessity to find new sources of saving that encourage the resurgence of the market rules and its intrusion in the shipper-LSP partnerships.

For the shipper, the second way of walking away from the purely relational exchange consists in associating with one or many competitors and, with them, to turn to a single LSP, in order to help the latter work at a larger scale and optimise its flow management. Many dyads that were previously separated are now together. The key elements are based this time, not on the opening to competition but, on the pooling of resources that the LSP dedicates to the group of shippers that work with him. The evolution of the VMI towards pooling shows this approach perfectly. As Camman \& Livolsi (2009) have shown, the VMI has developed at the initiative of small dynamic industrial groups (Benedicta, Nutrimaine and Lustucru in one of the examples of the French market analysed by the authors). To exceed the limits and succeed in increasing to a trucks' load factor, the shippers have gathered and have developed a pooling approach with a unique LSP (FM Logistic in the aforementioned example). LSPs have not played a leading role in the conception of this new measure, initiated by the shippers, but they were associated in the definition of the piloting rules that allowed synchronizing flows. Figure 2 shows the physical pooling process implemented by FM Logistic within the Sphinx project (one million pallets delivery per year, 1.4 billion $€$ sales).

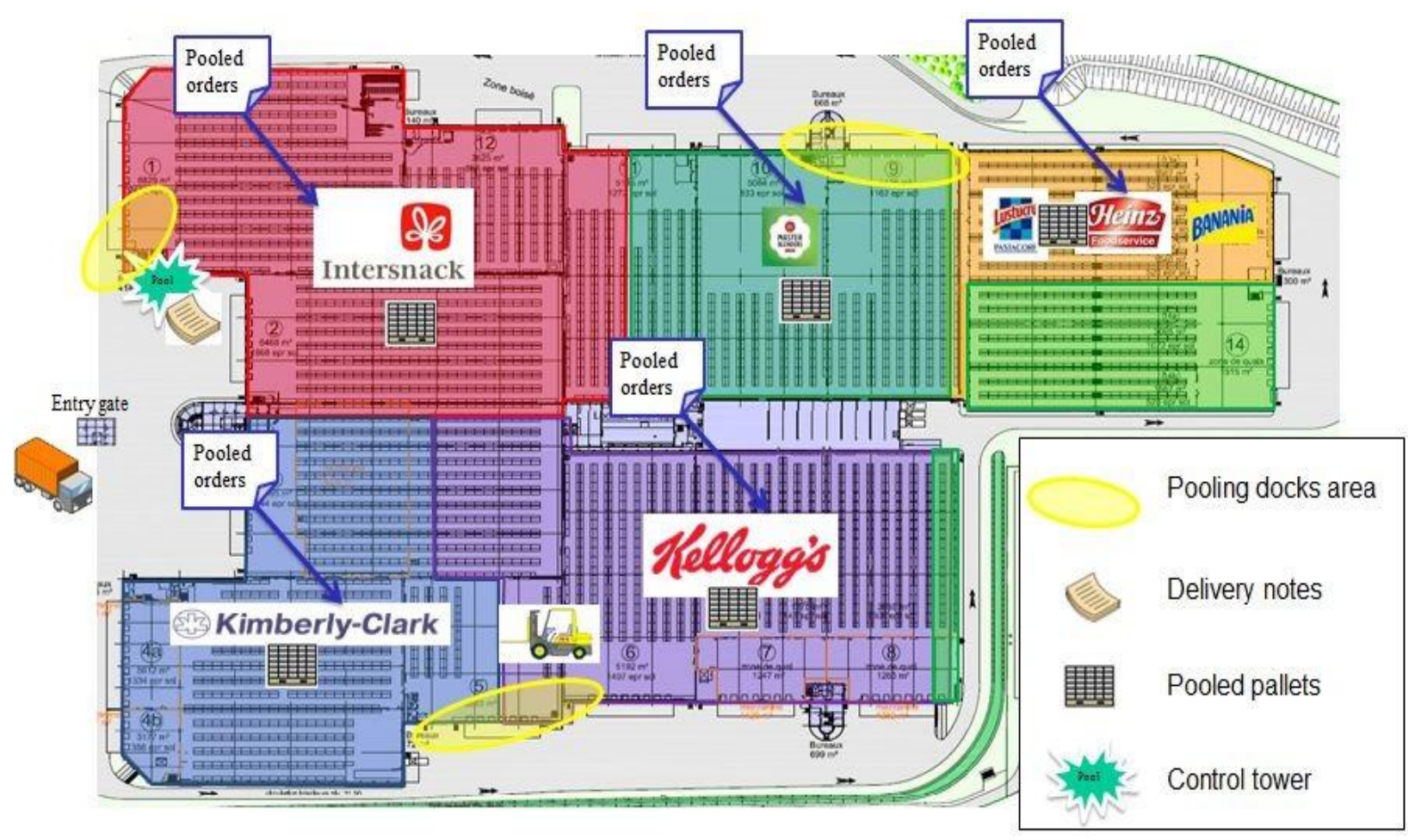

Source: Company document (2014).

Figure 2. FM Logistic: a leading role within the Sphinx project

The LSP is also likely to move away from the relational paradigm. In the exchanges between companies, the two parties are active and develop strategies, even when the balance of powers is maladjusted. These strategies answer each other but are not necessarily matching: purchasers and suppliers do not dispose of the same levers for action. For a supplier, in this case a LSP, the transactional perspective embedded in the relational register consists, not in using the 
incentive of competition, but rather in conceiving an offer that enables to broaden the access to the market. It leads to give up the exchanges, by developing a logistical service designed to fit a larger number and by offering it to all companies of that targeted segment in the framework of a common user contract. It would be possible, in this case, to make reference to governance mechanisms evoked in the literature, in particular, the informal mechanisms resulting from the agreed-upon processes at the starting point of social relationships, which have for purpose to face modifications of the environment through more flexibility (Poppo \& Zenger, 2002).

Some LSPs orientate themselves progressively on this route. They have started by adopting the relational perspective in order to fulfil the manufacturers' and large retailers' expectations that, after having developed their own account logistics, have wanted to outsource these activities by controlling them indirectly through the establishment of closed dyadic relationships. They have then endeavoured to reinforce their position by offering high value added services to the main manufacturers and retailers. Amongst them, the more dynamic have recently acquired new strategic skills by answering the requests of shippers wishing to benefit from the advantages of pooling (Camman \& Livolsi, 2009). Thanks to their capacity to manage the relationship with numerous clients in a coordinated way, these LSPs can now offer services based on the gathering of flows to companies that have not yet opted for that formula. This does not exclude the customisation of certain elements of the service, with co-packing for example. However, in this new type of offer, the transactional component is stronger. Based on the reinforcement of strategic skills, the more powerful LSPs start to offer a more standardised service, by targeting small to medium manufacturers with which the balance of powers is more favourable.

In the exchanges between shippers and LSPs, pooling can also be introduced by a third party. This can be seen in the field of urban logistics (Paché, 2010). Under the pressure of local authorities, pooling systems for delivery in city centres are progressively implemented (Töbelmann, 2011). They lead to a sharing of logistical resources between various competing shippers, particularly when it comes to stocking and the planning of delivery routes; it is the case of La Rochelle, in France (see Box 3). Thus, large retailers that had entrusted their stores' purchasing to a LSP by developing a relational exchange see the local authorities impose on this LSP to also deliver competitors' stores. The local authorities then become the master of the game and define the contractual parameters of the frame in which the LSP develop its activity. For the LSP, the shipper is just an undifferentiated client for which no specific investment will be done. Administrative procedures, as well as the political factors, play a decisive role in this measure which resembles domesticated markets described by Arndt (1979).

\begin{tabular}{l} 
Box 3. Sharing Logistical Resources In A Urban Context: The La Rochelle Case \\
\hline The idea of consolidating goods on the urban periphery for subsequent delivery to retail outlets has been explored since the \\
1970s, but never successfully implemented. The closest examples of city logistics in Germany were based on freight forwarding \\
companies, but these were not driven primarily by environmental concerns. After a three-year trial in the framework of the \\
ELCIDIS project (2002-2005), which focused on goods distribution using electric vehicles, it was decided to improve the \\
efficiency of the logistics platform and define a methodology for developing a systematic approach to urban goods \\
transportation that could be transferred to other towns in the La Rochelle Urban Community, in France. The measure was \\
aimed specifically at enlarging the area of the city covered by the logistics system, defining the physical and managerial \\
boundaries to be drawn between the industrial supply chain and city logistics, and promoting the use of clean vehicles. The \\
main activities are focused on making specific arrangements with distributors regarding the use of delivery hours and \\
coordination.
\end{tabular} Source: retrieved from http://civitas.eu, March 11, 2014.

This extreme pooling, imposed by an entity that disposes of sufficient legitimacy to constrain the action of private companies (Chanut \& Paché, 2013), corresponds to a particular type of hybridisation in which the transactional component is prevalent; it is also characterised by a forced loyalty to the hub created by the local authority and by the establishment of an obligated coopetitive strategy between the shippers, in the meaning of Bengtsson \& Kock (2000). The forced pooling, in this case, does not concern the large stores, such as hypermarkets, that are localised in peripheral urban zones. On the contrary, today it develops principally in the field of e-grocery and small shops, as convenience stores, whose flows are destined to congested city centres. However, with the growing importance of environmental constraints that weigh on local authorities, its application will inevitably stretch out to other activities. For that matter, Rodrigue (2012) analyses the geography of clusters in the USA, mainly through the phenomenon of relational proximity in which the LSPs play a major arbitrary role in the development of coopetitive strategies between shippers. It leads to a differentiation between two shapes of hybridisation of exchanges in the logistics industry: a sequential 
hybridisation in which the transactional episodes take part in a durable relationship, and a structural hybridisation based on the pooling of logistical resources, within which the elements of transactional nature coexist with the relational exchange (see Table 1). These two types of hybridisation do not have the same impact on the inter-organisational exchanges as they obey to different approaches, in the way that the collaborative supply chain is considered by the partners, as well as in the steering of operations that they build together.

Table 1: Hybridisation of exchanges between shippers and LSPs

\begin{tabular}{|c|l|}
\hline $\begin{array}{c}\text { Sequential hybridisation } \\
\text { Transactional episode in the durable relationship between a } \\
\text { shipper and its privileged LSP }\end{array}$ & $\begin{array}{l}\text { Occasional and limited in time infidelity from the shipper } \\
\text { vis-à-vis his LSP partner } \\
\text { Temporary recourse to a rival LSP for the management of } \\
\text { a portion of the flows }\end{array}$ \\
\hline $\begin{array}{c}\text { Structural hybridisation } \\
\text { Pooling of logistical resources with the establishment of } \\
\text { common measures for various shippers (multipick, multidrop, } \\
\text { etc.) }\end{array}$ & $\begin{array}{l}\text { Pooling of a LSP logistical resources for a small number } \\
\text { of large shippers, initiated by them and depending on their } \\
\text { expectations } \\
\text { Pooling of logistical resources for a set of mid-size } \\
\text { shippers, resulting in the adjustment of a standard offer by } \\
\text { certain LSPs that have become more powerful } \\
\text { General pooling of resources of LSPs in a given zone, } \\
\text { imposed by the local authority in charge of administering } \\
\text { the zone }\end{array}$ \\
\hline
\end{tabular}

\section{Impact Of The Sequential Hybridisation And The Structural Hybridisation}

For want of being easy to implement, the sequential perspective is simple in its principle. It is based, as explained previously, on an opening to competition, limited in time and space. When this opening causes the termination of exchanges with the regular LSP, strictly speaking, there is no hybridisation; a relationship replaces another or gives way to a set of transactions. When the partner is not abandoned for good but that it is only a simple infidelity destined to put pressure on him or to seize an opportunity, there is hybridisation because the two paradigms string and articulate together: the relational exchanges momentarily give way to transactional exchanges before forcing itself anew. This hybridisation has consequences on the governance of inter-organisational exchanges. The transactional episode has an impact on the way the LSP, that has been temporarily abandoned, dread the pursuit of the collaboration with the shipper. Indeed, this LSP is encouraged to redouble its efforts to postpone the appearance of the next transactional episode, but it is also lead to question itself on the engagement in the relationship; the event of a break-up or a downgrading to the rank of simple supplier tends to discourage its development of a specific asset-except if it causes high switching costs for both parties and makes the shipper loyal. When the hybridisation is structural and results in the pooling of logistical resources of a LSP, this tends to modify the task sharing and the contractual relationships between this LSP and the concerned clients (see Figure 3). The pooling affects the task sharing as it is accompanied by a modification of the role and the weight of the partners in the conception of the supply chain. The pooling of means is a source of savings and a learning factor, but it leads to constraints, rigidity and compromise costs (Porter, 1985). Compromise costs are particularly important for the analysis of the consequences of pooling. 

Dedicated
Shared user
contract
Common user
contract

$\begin{array}{ccc}\begin{array}{c}\text { Dedicated } \\ \text { contract }\end{array} & \begin{array}{c}\text { Shared user } \\ \text { contract }\end{array} & \text { Common user } \\ \text { contract }\end{array}$

\begin{tabular}{|c|c|c|c|}
\hline $\begin{array}{l}\text { (closed dyad with } \\
\text { mutual } \\
\text { personalised } \\
\text { adjustments) }\end{array}$ & $\begin{array}{l}\text { pooling initiated collectively } \\
\text { by a small number of shippers, } \\
\text { adapted and managed by this } \\
\text { group }\end{array}$ & $\begin{array}{l}\text { pooling by progressive } \\
\text { standardisation of the offer } \\
\text { initiated by a number of } \\
\text { powerful LSPs }\end{array}$ & $\begin{array}{l}\text { (standard exchanges } \\
\text { open to all actors of } \\
\text { the market) }\end{array}$ \\
\hline
\end{tabular}

Figure 3: The Task Sharing In The Pooling And Contracts

When the small number of shippers make an alliance to reduce the costs and optimise the management flow by sharing the LSP's resources, they manage to find an arrangement quite easily when their activities are similar and their strategies coincide. However, this arrangement causes new constraints and deprives each shipper of some of the advantages that the purely relational exchange confers. The interface with the LSP no longer shows the tailor-made adjustments that only a close dyadic relationship can obtain. In the collective negotiation aiming at planning the pooling, all the shippers are lead to make compromises by giving up the taking into account of a given particularity of their activity, for example, a specific procedure of form postponement (Trentin, 2011). They must all accept the establishment of a common norm, adapted to their group, in order to be capable of coordinating their processes and share the LSP's resources by collaborating with him. Additionally, when the shippers do not have an equivalent negotiating power, which is often the case, a number of them are brought to make more important efforts than the others. These shippers are forced to unite for a solution defended by the group leaders. The agreement seems to be globally satisfying for them and profitable for all. However, they know that the retained solutions are under-optimal for them and more advantageous for the shippers that dominate the coalition, and that have weighed more heavily in the definition of common rules.

When the number of concerned shippers increase and that none of them are capable of imposing themselves, the LSP has a more important role in the elaboration of the compromise. The collaboration with the shippers is, then, limited. Benefiting from a more favourable balance of powers, the LSP is indeed leaded to propose an offer likely to be accepted by the manufacturers as a whole and concerned retailers, an offer that highlights the common denominator by neglecting their specific features. Thus, in the field of urban logistics, the restrictive framework set by the local authorities sets out the guide lines of the task sharing between shippers and LSPs, this leaves very little space for cooperation. Certain concrete modalities of this sharing can however be jointly refined and adjusted by the shippers and the LSPs, depending on their respective power, but also on the experience acquired in the operations requiring a sharing of resources (Chanut \& Paché, 2013). In the particular cases of urban logistics, the pooling imposed by the local authorities constitutes a normalised frame that favours the establishment of a transactional perspective in the exchanges between shippers and LSPs. This perspective then tends to predominate but, there again, the search for customer loyalty or the decrease of the costs of changing suppliers can stabilise the exchanges and give way to the partial forms of relational exchange.

With the pooling of the LSP's resources, the character of the contract tends to change: from a dedicated contract to a shared user or a common user contract (Cooper et al., 1993). When a small number of innovative shippers gather to make business with a common LSP in an organised manner, the relationship is based on a shared contract; in this case, the level of switching costs is more important for the shipper than for the LSP (see Box 4). In the latter, even if the balance of power is evenly distributed, the relational perspective is still present as the shippers and the LSP must define collectively the rules maintained over time to ensure the steering of the supply chain. For the powerful LSPs that struggle to develop a pooling offer on the SME market, the common user contract is necessary. The standardisation is indeed a key element of this strategy. Consequently, the transactional dimension tends to prevail. Elements falling under the relational component can, however, persist if the LSP at the root of the standardisation seeks to gain loyalty from the aimed segment client. 
Box 4. The Question Of Switching Costs

Globalization, competition and shifting economic conditions are now causing shippers to continuously re-evaluate their supply chain strategies, including their relationships with LSPs. Many shippers seem to view putting contracts out for bid and shortening contract lengths as important steps in containing costs and taking advantage of the competitive environment among LSPs. However, neither short-term contracts nor the solicitation and onboarding of new providers help to establish solid foundations for mature, strategic shipper-LSP relationships. Understanding the cost of change - both to the shipper and to the shipper's customers - is critical to organizations that are outsourcing or are considering changing LSPs. The strategy of switching providers can impact several relevant types of costs, a few of which are listed below: relational switching costs (personal and brand relationship costs, which involves psychological or emotional discomfort), procedural switching costs (economic risk and time and effort spent on evaluation, learning and set up costs) and financial switching costs (benefits loss and financial loss).

Source: Capgemini Consulting (2014).

\section{DISCUSSION AND CONCLUSIONS}

The case of the logistics industry is significant of the hybridisation of inter-organisational exchanges. The diversity of relationships between shipper and LSP, and the fact that these types of relationships usually intertwine all along the lifespan of inter-organisation exchanges, underlining that it is impossible to define the one best way. The only constraint is to propose a high level of logistics process responsiveness understood as the ability to address changes in customer demand (Thatte, 2013). It questions, in a more general manner, the future of the exchanges based on the relational paradigm (Hofenk et al., 2011). Two interrogations prevail, for which our hybridisation analysis allows to bring a first set of answers:

- $\quad$ Are we facing recoil of the referential shape of the relational paradigm that is based on the shipper-LSP closed dyad? The sequential hybridisation stays centred on the dyad, but it makes it unstable by introducing repeated infidelity. The existence of transactional episodes can, momentarily, increase the performance of interorganisational relationships through creating competition between manufacturers and a correlated decrease of the price of the service, but what about the long term commitment of partners for a more efficient supply chain? The structural hybridisation, that is becoming more frequent, suggests, on the other hand, that the competition between dyads will, for certain activities, be progressively replaced by a competition between coalitions of shippers and LSPs. For these coalitions, the determining element resides in the efficiency of the sharing of logistical resources and the importance of savings it makes. The command of the political process of the definition of collective norms proves to be decisive for the functioning of these intermediary entities, that are located between the client-supplier marriage and the market open to anyone, and the tightly combined competition and coopetition between the actors.

- In terms of managerial recommendations, should we generalise the hybridisation of the process or, on the contrary, should we save them for certain services, which will lead to an analysis in terms of segmentation benefit? Two diverging but complementary orientations emerge from this design. For the basic operations (collection, stocking, delivery), the important economic advantages of pooling suggest that the latter are called to expand, with, at stake, a progressive standardisation of the offer and a growing weight of the transactional component. Simultaneously, LSPs increase their efforts to offer additional innovative services such as copacking and kitting, in this field, partnerships with shippers that see in these innovations a differentiating factor.

The advantage of hybridisation analysis is that it raises the question of the necessary dichotomy in the manner of approaching inter-organisational exchanges. It leads in particular to the challenging of the pertinence of the evolution model, the transactional to the relational paradigm, presented like a universal pattern. The hybridisation also raises the question of the stability of mixed configurations, associating market and hierarchy, with a necessary return on the fundamentals issuing from Williamson's (1991) studies. Indeed, the rising of hybrid forms, for example in terms of dynamic networks (Miles \& Snow, 1986), questions the nature of long-term relationships between stakeholders that engage themselves in the formulation of a common collective project. Contrarily to what one could think of first, a hybrid form in the meaning of Williamson (1991) is capable of surviving one or many transactional episodes, and it is even possible that it reinforces it. It is this paradoxical reality that needs to be studied in depth for a better understanding of inter-organisational exchanges. 


\section{AUTHORS INFORMATION}

Hervé Fenneteau is Professor of Marketing at the Université Montpellier I, France. He is a member of Montpellier Research in Management (MRM) in Montpellier. In his books, articles and book chapters, he is particularly interested in the marketing aspects of supplier-buyer exchanges. Email: herve.fenneteau@ univ-montp1.fr.

Gilles Paché is Professor of Retailing and Supply Chain Management at the Aix-Marseille Université, France. He has more than 300 publications in the forms of journal papers, books, edited books, edited proceedings, edited special issues, book chapters, conference papers, and reports. He is Deputy Director of the Centre de Recherche sur le Transport et la Logistique (CRET-LOG) in Aix-en-Provence, and his major interests are network organizations, supply chain management, and retail operations management. Email: gilles.pache@univ-amu.fr (corresponding author)

\section{REFERENCES}

Angué, K. (2009). Rôle et place de l'abduction dans la création de connaissances et dans la méthode scientifique peircienne. Recherches Qualitatives 28(2) 65-94.

Arndt, J. (1979). Toward a concept of domesticated markets. Journal of Marketing 43(4) 69-75.

Bengtsson, M. and Kock, S. (2000). "Coopetition" in business networks-To cooperate and compete simultaneously. Industrial Marketing Management 29(5) 411-426.

Camman, C. and Livolsi, L. (2009). La gestion mutualisée des approvisionnements: une opportunité stratégique pour les prestataires de services logistiques. Gestion 2000 26(3) 59-74.

Chanut, O. and Paché, G. (2013). Le PSL à l'épreuve de la logistique urbaine: des signaux faibles porteurs de profondes mutations. Logistique \& Management 21(1) 31-44.

Clinton, S. (2008). Importance of technology investments in the logistics service providers: a case study of UPS and its use of online tools. Journal of Applied Business Research 24(2) 67-80.

Cooper, J., Browne, M. and Peters, M. (1993). European logistics: markets, management and strategy. Oxford: Blackwell Publishers, $2^{\text {nd }}$ ed.

Dagnino, G.-B. and Rocco, E., Eds. (2011). Coopetition strategy: theory, experiments and cases. London: Routledge.

Dubois, A. and Fredriksson, P. (2008). Cooperating and competing in supply networks: making sense of a triadic sourcing strategy. Journal of Purchasing \& Supply Management 14(3) 170-179.

Ellinger, A., Keller, S. and Bas, A. (2010). The empowerment of frontline staff in 3PL companies. Journal of Business Logistics 37(4) 353-366.

Eriksson, P. (2008). Procurement effects on coopetition in client-contractor relationships. Journal of Constuction Engineering and Management 134(2) 103-111.

Fulconis, F. and Paché, G. (2008). Et si les comportements opportunistes amélioraient la performance des relations au sein des réseaux d'affaires? Gestion 2000 25(4) 19-46.

Fulconis, F., Paché, G. and Roveillo, G. (2011). La prestation logistique: origines, enjeux et perspectives. Caen: Editions Management \& Société.

Grönroos, S. (1996). Relationship marketing: strategic and tactical implications. Management Decision 34(3) 5-14.

Gummesson, E. (2008). Total relationship marketing: marketing management, relationship strategy and CRM approaches for the network economy. London: Butterworth-Heinemann, $3^{\text {rd }}$ ed.

Hofenk, D., Schipper, R., Semeijn, J. and Gelderman, C. (2011). The influence of contractual and relational factors on the effectiveness of third party logistics relationships. Journal of Purchasing \& Supply Management 17(3) $167-175$.

Lacoste, S. (2012). "Vertical coopetition": the key account perspective. Industrial Marketing Management 41(4) 649658.

Large, R. (2007). The influence of customer-specific adaptations on the performance of third party logistics relationships-Document studies and propositions. International Journal of Logistics: Research and Applications 10(2) 123-133.

Large, R., Kramer, N. and Hartmann, R. (2011). Customer-specific adaptation by providers and their perception of 3PL-relationship success. International Journal of Physical Distribution \& Logistics Management 41(9) 822838. 
Li, F. and Nicholls, A. (2000). Transactional or relationship marketing: determinants of strategic choices. Journal of Marketing Management 16(5) 449-464.

Marty, N. (2008). L'eau embouteillée: histoire de la construction d'un marché. Entreprises \& Histoire 50 86-99.

Medina, P. and Paché, G. (2007). The entrenchment strategy of logistics service providers: towards a sequential cooperation-competition process? Journal of Transport \& Supply Chain Management 1 65-78.

Miles, R. and Snow, C. (1986). Organizations: new concepts for new forms. California Management Review 28(3) 6273.

Morgan, R. and Hunt, S. (1994). The commitment-trust theory of relationship marketing. Journal of Marketing 58(3) 20-38.

Noordewier, T., John, G. and Nevin, J. (1990). Performance outcomes of purchasing arrangements in industrial buyervendor relationships. Journal of Marketing 54(4) 80-93.

Paché, G. (2010). Logistique urbaine mutualisée: quelle stratégie de différenciation pour le commerce en ligne? Revue Française de Gestion Industrielle 29(2) 27-47.

Poppo, L. and Zenger, T. (2002). Do formal contracts and relational governance function as substitutes or complements? Strategic Management Journal 23(8) 707-725.

Porter, M. (1985). Competitive advantage: creating and sustaining superior performance. New York (NY): The Free Press.

Rindfleisch, A. and Heide, J. (1997). Transaction cost analysis: past, present, and future applications. Journal of Marketing 61(4) 30-54.

Rodrigue, J.-P. (2012). The geography of global supply chains: evidence from third-party logistics. Journal of Supply Chain Management 48(3) 15-23.

Roques, T. and Michrafy, M. (2003). Logistics service providers in France-2002 survey: actors' perceptions and changes in practice. Supply Chain Forum: An International Journal 4(2) 34-52.

Thatte, A. (2013). Supply chain responsiveness through modularity based manufacturing practices: an exploratory study. Journal of Applied Business Research 29(3) 743-764.

Tixier, D., Mathe, H. and Colin, J. (1996). La logistique d'entreprise: vers un management plus compétitif. Paris: Dunod.

Töbelmann, M. (2011). Public policies on sustainable logistics and the impact on third party logistics providers. Munich: Grin Verlag.

Trentin, A. (2011). Third-party logistics providers offering form postponement services: value propositions and organisational approaches. International Journal of Production Research 49(6) 1685-1712.

Williamson, O. (1991). Comparative economic organization: the analysis of discrete structural alternatives. Administrative Science Quarterly 36(2) 269-296. 